\title{
Comparing two methods for deriving dietary patterns associated with risk of metabolic syndrome among middle-aged and elderly Taiwanese adults with impaired kidney function
}

Adi Lukas Kurniawan ${ }^{1,2}$, Chien-Yeh Hsu ${ }^{3,4}$, Hsiu-An Lee $^{5}$, Hsiao-Hsien Rau $^{6}$, Rathi Paramastri ${ }^{1}$, Ahmad Syauqy ${ }^{1,7}$ and Jane C.-J. Chao ${ }^{1,4,8^{*}}$ (i)

\begin{abstract}
Background: Dietary patterns were associated with the risk of chronic disease development and outcome-related diseases. In this study, we aimed to compare the correlation between dietary patterns and metabolic syndrome (MetS) using two methods for identifying dietary patterns.

Methods: The participants $(n=25,569)$ aged $\geq 40$ years with impaired kidney function were retrieved from Mei Jau (MJ) Health Screening database from 2008 to 2010. Dietary patterns were identified by principal component analysis (PCA) and reduced rank regression (RRR) from twenty-two food groups using PROC FACTOR and PROC PLS functions.

Results: We identified two similar dietary pattern characteristics (high intakes of deep fried foods, preserved or processed foods, dipping sauce, meat, sugary drinks, organ meats, jam/honey, fried rice/flour products, instant noodles and eggs) derived by PCA and RRR. Logistic regression analysis revealed that RRR-derived dietary pattern scores were positively associated with an odds ratio $(\mathrm{OR}=1.70,95 \% \mathrm{Cl}: 1.56,1.86)$ of having MetS than PCA-derived dietary pattern scores $(\mathrm{OR}=1.38,95 \% \mathrm{Cl}: 1.27,1.51)$. The correlations between RRR-derived dietary pattern scores and elevated systolic and diastolic blood pressure $(\mathrm{OR}=1.30$ for both) or low high density lipoprotein cholesterol in women $(O R=1.32)$ were statistically significant but not significant in PCA-derived dietary pattern scores.
\end{abstract}

Conclusions: Our findings suggest that RRR gives better results when studying behavior related dietary patterns in association with MetS. RRR may be more preferable to provide dietary information for developing dietary guidelines among people with MetS. Further studies with prospective measurements are needed to verify whether RRR is a useful analytic tool for the association between dietary patterns and other chronic diseases.

Keywords: Dietary pattern analysis, Metabolic syndrome, Principal component analysis, Reduced rank regression

\footnotetext{
*Correspondence: chenjui@tmu.edu.tw

'School of Nutrition and Health Sciences, College of Nutrition, Taipei Medical University, 250 Wu-Hsing Street, Taipei 11031, Taiwan

${ }^{4}$ Master Program in Global Health and Development, College of Public Health, Taipei Medical University, 250 Wu-Hsing Street, Taipei 11031, Taiwan

Full list of author information is available at the end of the article
}

(c) The Author(s). 2020 Open Access This article is licensed under a Creative Commons Attribution 4.0 International License, which permits use, sharing, adaptation, distribution and reproduction in any medium or format, as long as you give appropriate credit to the original author(s) and the source, provide a link to the Creative Commons licence, and indicate if changes were made. The images or other third party material in this article are included in the article's Creative Commons. licence, unless indicated otherwise in a credit line to the material. If material is not included in the article's Creative Commons licence and your intended use is not permitted by statutory regulation or exceeds the permitted use, you will need to obtain permission directly from the copyright holder. To view a copy of this licence, visit http://creativecommons.org/licenses/by/4.0/. The Creative Commons Public Domain Dedication waiver (http://creativecommons.org/publicdomain/zero/1.0/) applies to the data made available in this article, unless otherwise stated in a credit line to the data. 


\section{Background}

Chronic disease such as chronic kidney disease and cardiovascular disease has been elevated in the older people, and might be worsened in the presence of metabolic syndrome (MetS) [1]. MetS is defined as a cluster of metabolic disorders characterized by central obesity, dyslipidemia, elevated blood pressure and hyperglycemia [2]. Individuals with MetS were more likely to develop impaired kidney function or the later stage of chronic kidney disease [3]. Previous studies found that the prevalence of metabolic syndrome among dialytic patients in the United States and Finland was 69.3\% [4] and 55.7\% [5], respectively.

The risk of metabolic syndrome was correlated with dietary intake. Dietary patterns have been used to assess the association between dietary intake and chronic disease [6]. Dietary patterns may provide better information regarding the diet and disease relationship beyond the effects of dietary intake for single nutrient or food [7]. Dietary patterns in relation to MetS were investigated in previous studies. The Western dietary pattern characterized by high intakes of protein, processed foods and refined grains was positively associated with the prevalence of MetS, whereas the healthy dietary pattern with high consumption of vegetables, fruits and dairy products was negatively correlated with MetS $[8,9]$.

Various methods derived dietary patterns in the epidemiological studies including hypothesis-driven method (a priori), data-driven method (a posteriori) or a combination with these two methods [10]. Principal component analysis (PCA), a data-driven method, generates dietary patterns based upon inter correlations between original food intake variables. PCA tends to explain as much variation in dietary intake as possible, and is more likely to represent actual dietary habits in population [11]. However, PCA may have poor correlation with disease risk because behavior-related patterns are not necessarily predictors of the disease of interest [11]. To overcome this issue, a combination method using both a priori and a posteriori approach such as reduced rank regression (RRR) was recently proposed to derive the dietary pattern. This RRR method can explain as much variation in response to disease as possible. Therefore, to compare the dietary patterns derived from PCA with those generated using the RRR method provides more reliable correlation with the disease outcome although the foods in RRR-derived dietary pattern may not be behaviorally associated [12]. A cohort study showed that an increased RRR score was associated with a higher odds ratio of having MetS than an increased PCA pattern in a Northern German population as comparing both PCA and RRR methods [13]. However, the numbers of the participants in the previous study were relatively modest. Therefore, study in the larger population is needed.
Considering that chronic kidney disease has been elevated in the older people, and might be worsened in the presence of MetS, we hypothesized that PCA- and RRRderived dietary patterns were different in relation to predict the risk of MetS among older people with impaired kidney function. The objective of this study was to investigate and compare the association between dietary patterns and risk of metabolic syndrome among middleaged and elderly Taiwanese adults with impaired kidney function using both PCA and RRR methods to derive the dietary pattern. In comparison with two different research methodologies, we expected that the dietary pattern derived from RRR method was more strongly associated with MetS among middle-aged and elderly Taiwanese adults with impaired kidney function.

\section{Methods}

\section{Study participants}

The data of the participants with impaired kidney function were retrieved from the database of the Mei Jau (MJ) private health screening centers in Taiwan from 2008 to 2010. The MJ Group has four health screening centers located in Taipei, Taoyuan, Taichung and Kaohsiung, and provides health examination periodically to its members. Participants completed a questionnaire about sociodemographic data, lifestyle and dietary habits prior to anthropometric and biochemical measurements. All participants signed the informed consent authorized by the MJ health screening centers, and the data without personal identification were used for research only. Eligible participants $(n=112,140)$ were aged $\geq 40$ years and had impaired kidney function with estimated glomerular filtration rate $($ eGFR $)<90 \mathrm{~mL} / \mathrm{min} / 1.73 \mathrm{~m}^{2}$ and positive urinary protein. We excluded those who had any types of cancer or virus infection $(n=48,169)$, history of any transplantation $(n=1765)$, error values in blood analysis and anthropometric measurements $(n=1266)$, missing data in dietary assessment and other covariates $(n=26$, $605)$, not complete the questionnaire $(n=212)$ and multiple entries $(n=8554)$. Finally, 25,569 participants were included in the analysis. Taipei Medical University-Joint Institutional Review Board approved this study (TMUJIRB N201802006).

\section{Assessment of anthropometric and biochemical variables}

Body weight and height were observed by an autoanthropometer (Nakamura KN-5000A, Tokyo, Japan), and body mass index (BMI) was calculated as the ratio of weight $(\mathrm{kg})$ to the square of height $\left(\mathrm{m}^{2}\right)$. Waist or hip circumference was measured by a flexible tape. Blood pressure was recorded twice at a 10-min interval after resting for $5 \mathrm{~min}$ in the sitting position using a standardized sphygmomanometer. Participants were overnight fasting at least for $8 \mathrm{~h}$ before a blood test. 
Uncompensated Jaffe method with alkaline picrate kinetic test was used to measure creatinine levels and eGFR was calculated using the Chronic Kidney Disease Epidemiology Collaboration (CKD-EPI) equation [14]. Meanwhile, urinary protein was measured by Roche Miditron $\mathrm{M}$ semiautomated computer-assisted urinalysis system (Combur10 test M dipstick, Basel, Switzerland). Fasting blood glucose (FBG) and blood lipids such as triglycerides (TG), high density lipoprotein cholesterol (HDL-C), low density lipoprotein cholesterol (LDL-C) and total cholesterol (TC) were analyzed (Toshiba C8000 auto-analyzer, Tokyo, Japan) at the MJ health screening central laboratory. The coefficient of variation for all variables ranged from 1 to $3 \%$. Hypertension and type 2 diabetes were defined as described in the previous study [15]. The definition of hypertension included at least one of the followings: systolic blood pressure $\geq 140 \mathrm{mmHg}$, diastolic blood pressure $\geq 90$ $\mathrm{mmHg}$, use of antihypertensive medication or selfreported hypertension. The definition of diabetes included at least one of the following: (1) FBG $\geq 7.0 \mathrm{mmol} / \mathrm{L}$ ( $\geq 126$ $\mathrm{mg} / \mathrm{dL}$ ), (2) use of hypoglycemic medication or (3) selfreported diabetes. The definition of MetS for Asians was to have at least three or more of the followings: (1) waist circumference $\geq 90 \mathrm{~cm}$ in men or $\geq 80 \mathrm{~cm}$ in women, (2) systolic blood pressure $(\mathrm{BP}) \geq 130 \mathrm{mmHg}$, diastolic $\mathrm{BP} \geq$ $85 \mathrm{mmHg}$ or on anti-hypertensive drug treatment, (3) $\mathrm{TG} \geq 1.70 \mathrm{mmol} / \mathrm{L}(150 \mathrm{mg} / \mathrm{dL})$ or on treatment for lipid abnormality, (4) HDL-C $<1.03 \mathrm{mmol} / \mathrm{L}(40 \mathrm{mg} / \mathrm{dL})$ in men, $<1.30 \mathrm{mmol} / \mathrm{L}(50 \mathrm{mg} / \mathrm{dL})$ in women or on treatment for lipid abnormality, (5) FBG $\geq 5.6 \mathrm{mmol} / \mathrm{L}$ (100 $\mathrm{mg} / \mathrm{dL}$ ) or on anti-diabetic drug treatment [16].

\section{Assessment of dietary habits and other covariates}

Dietary habits were obtained using standardized and validated self-administered semi quantitative food frequency questionnaire (SQ-FFQ) [17, 18]. Initially, the questionnaire had 85 closed-ended questions on individual food items, twenty-two non-overlapping food groups were classified after standardization and validation as mentioned previously [19]. Participants reported the consumption frequency of each food group on a daily or weekly basis in the past month [19]. The consumption frequency described by the portion size of a bowl, a glass or a serving for one-time intake was categorized into five response options from the lowest to the highest frequency as mentioned previously [19]. The detailed information about the food groups are provided in Additional file 1: Table S1.

Demographic (age, gender, education level, income and marital status) and lifestyle variables (smoking, drinking, sleep quality and physical activity) were recorded using a self-administered questionnaire. Smoking status was classified as 'yes' if the participant smoked a cigarette occasionally or daily and as 'no' if otherwise.
Drinking alcohol was also categorized as 'no' $(<1$ time/ week) and 'yes' ( $\geq 1-2$ times/week). Physical activity was assessed by self-reporting intensity (light, moderate and heavy or intense), duration (hours) and frequency (per week) in the last 2 weeks. For sleep quality, participants filled the questions regarding sleep quality and average daily sleep duration in the last month. Sleep quality had five response options (difficulty to fall asleep, difficulty maintaining sleep, feeling of non-restorative sleep, use of sedatives or sleeping pills and no problem to sleep well), and sleep duration had six response options $(\leq 4,4-<6$, $6-<7,7-<8,8-<9$ and $>9$ h). We defined sleep quality as 'well' if the participants had $\geq 7 \mathrm{~h}$ of sleep duration with sleep quality of "no problem to sleep well" and as 'not well' if otherwise. For physical activity, the detailed examples of different intensities were described in the self-administered questionnaire. The metabolic equivalent task (MET) for different intensities of physical activity was determined according to previous study [20]. The MET expressed as hours per week was calculated by multiplying the corresponding MET coefficient by duration and frequency of physical activity.

\section{Statistical analysis}

The statistical analysis was performed by SAS 9.4 (SAS Institute Inc., USA) and STATA version 13 (StataCorp LP, College Station, TX, USA). Continuous (non-normal distributed) and categorical variables were presented as median (interquartile range, IQR) and number (percentage), respectively. The characteristics of study subjects with or without MetS were compared using MannWhitney or chi-square test for continuous or categorical data, respectively. The multivariable linear regression $[\beta$ and $95 \%$ confidence interval $(\mathrm{CI})]$ and logistic regression (odds ratio (OR) and 95\% CI) were used to examine the association of dietary pattern scores with the risk of MetS, components of MetS and their related biomarkers. The $P$-value for trend was analyzed using postestimation contrast and linear hypothesis test. Moreover, a subgroup analysis based on impaired kidney function categories was used for sensitivity analysis.

\section{Dietary patterns analysis}

Dietary patterns were identified by PCA and RRR methods using PROC FACTOR and PROC PLS, respectively. For PCA method, the orthogonal varimax rotation was used and we decided to retain only one from two factors for the comparison. For RRR method, six response variables (waist circumference, TG, HDL-C, systolic BP, diastolic BP and FBG) associated with MetS were used to generate the MetS-specific dietary pattern (Fig. 1). As six response variables were included in the MetS-specific dietary pattern, six factors were generated by RRR method. However, we only retained the first 


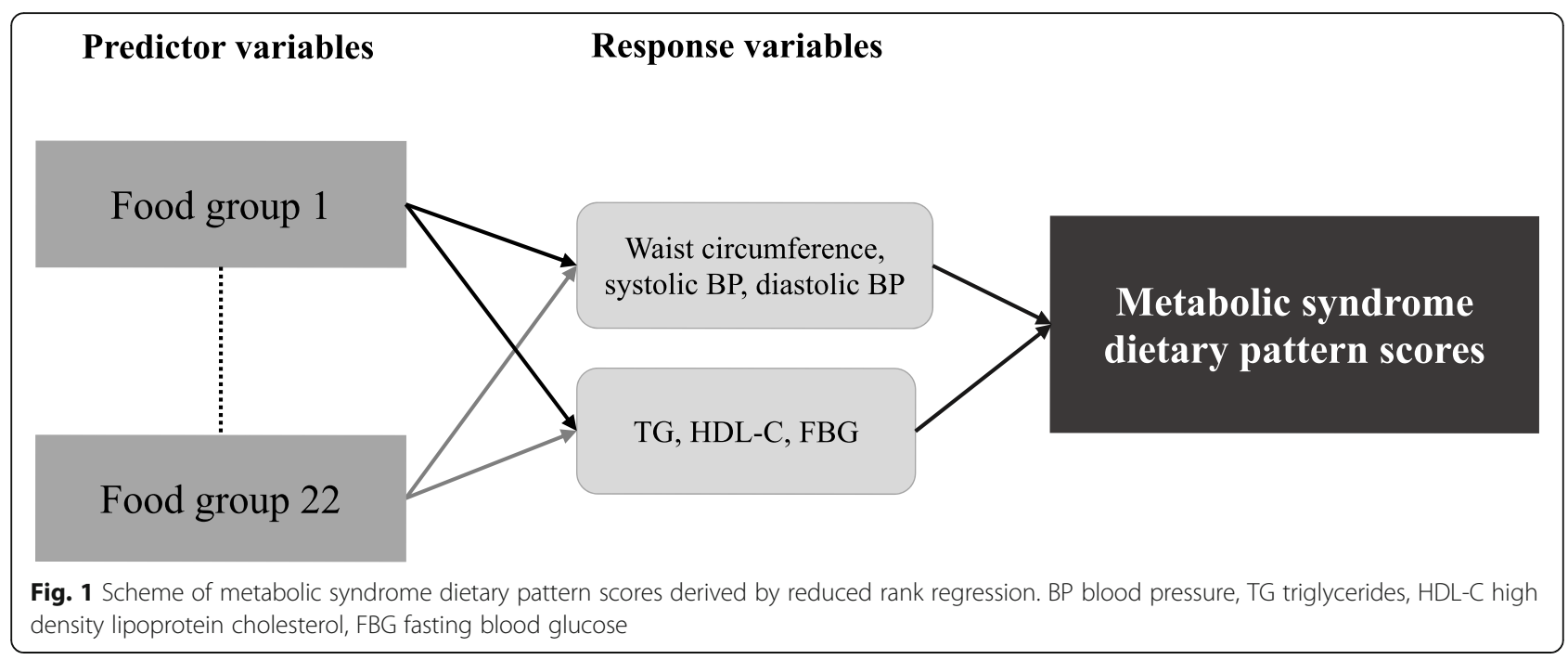

factor that explained the largest percentage (2.4\%) of variation in the response variables. The absolute factor loading (Pearson's correlation coefficient) values $\geq 0.20$ for each food group were the cutoff point to derive the dietary patterns in both PCA and RRR methods. Dietary pattern scores for an individual were calculated by summing intake frequency scores of food groups weighed by their respective factor loading values. However, six food groups had a factor loading $\geq 0.20$ in both PCA-derived dietary patterns. For characterizing the dietary pattern, these food groups could only belong to one factor with a greater factor loading value. Hence, the dietary scores of four food groups (beans/legumes, fried vegetables/salad dressing, rice/flour products and seafood) were neglected in the calculation of the first extracted dietary pattern (Additional file 2: Table S2). For further analysis, dietary pattern scores were divided into quartiles and two adjustment models were performed: model 1 adjusted for age and gender and model 2 adjusted for model 1 variables and education level, income, marital status, smoking, drinking, sleep quality, physical activity and cardiovascular disease status. A $P$-value $<0.05$ was considered statistically significant.

\section{Results}

The characteristics of the participants having impaired kidney function with or without MetS are presented in Table 1. The prevalence of MetS was 27.3\% $(n=6976)$ and $63.9 \%(n=4457)$ of participants with impaired kidney function were male. Participants having impaired kidney function with MetS were likely to be older and have lower kidney function (eGFR $72.0 \pm 12.0$ vs $75.9 \pm$ $9.6 \mathrm{~mL} / \mathrm{min} / 1.73 \mathrm{~m}^{2}, P<0.001$, data not shown), less MET, elevated BMI, higher waist-to-hip ratio and worse values for each component of MetS compared with those without MetS. The prevalence of each component of MetS was $24.6 \%$ for central obesity, $29.7 \%$ for elevated TG, $14.9 \%$ for reduced HDL-C, 42.4\% for elevated blood pressure and $58.0 \%$ for elevated FBG (data not shown). Participants having impaired kidney function with or without MetS statistically differed in the distribution of gender, education level, income, marital status, smoking and drinking. The prevalence of chronic diseases such as type 2 diabetes, hypertension and cardiovascular disease was higher in participants with MetS. Moreover, after adjusting for age, gender, education level, income, marital status, smoking, drinking, sleep quality and physical activity in model 2, participants having impaired kidney function with MetS had an increased risk of having eGFR $<60 \mathrm{~mL} / \mathrm{min} / 1.73 \mathrm{~m}^{2}(\mathrm{OR}=1.64,95 \%$ CI: 1.48 , $1.82, P<0.001$, data not shown).

\section{Dietary pattern analysis}

Pearson's correlation coefficients between food groups and both PCA- and RRR-derived dietary patterns are shown in Fig. 2. For the purpose of comparison, we only considered the first extraction pattern in both PCA and RRR methods because the first extraction pattern explained the most variations in predictor variables (food groups) in PCA-derived dietary pattern or response variables in RRR-derived dietary pattern. Moreover, the first pattern from both methods had relatively same characteristics, which generates easier interpretation. The first dietary pattern (fried-processed dietary pattern) derived by PCA method was characterized by frequent intake of deep fried foods, preserved or processed foods, dipping sauce, meat, sugary drinks, organ meats, jam or honey, fried rice or flour products, instant noodles and eggs. The pattern derived by RRR method seemed to have similar characteristics (high intakes in processed foods, organ meats, dipping sauce, meat, fried rice or flour products, rice or flour products, eggs, instant noodles 
Table 1 Characteristics of the participants with impaired kidney function by MetS status $(n=25,569)^{\text {a }}$

\begin{tabular}{|c|c|c|c|c|}
\hline & $\begin{array}{l}\text { All participants } \\
(n=25,569)\end{array}$ & $\begin{array}{l}\text { Participants without MetS } \\
(n=18,593)\end{array}$ & $\begin{array}{l}\text { Participants with MetS } \\
(n=6976)\end{array}$ & $P^{b}$ \\
\hline Age (years) & $51.0(14.0)$ & $49.0(13.0)$ & $55.0(16.0)$ & $<0.001$ \\
\hline Sex, $n(\%)$ & & & & $<0.001$ \\
\hline Male & $14,311(56.0)$ & $9854(53.0)$ & $4457(63.9)$ & \\
\hline Female & $11,258(44.0)$ & $8739(47.0)$ & $2519(36.1)$ & \\
\hline Education level, $n$ (\%) & & & & $<0.001$ \\
\hline Below university & $16,733(65.4)$ & $11,748(63.2)$ & $4985(71.5)$ & \\
\hline University or above & $8836(34.6)$ & $6845(36.8)$ & $1991(28.5)$ & \\
\hline Income (NTD/year), n (\%) & & & & $<0.001$ \\
\hline$<800,000$ & $11,620(45.4)$ & $8083(43.5)$ & $3537(50.7)$ & \\
\hline $810,000-1.6$ million & 9407 (36.8) & 7057 (37.9) & $2350(33.7)$ & \\
\hline$\geq 1.61$ million & $4542(17.8)$ & 3453 (18.6) & 1089 (15.6) & \\
\hline Marital status, n (\%) & & & & $<0.001$ \\
\hline No & $4050(15.8)$ & $2822(15.2)$ & $1228(17.6)$ & \\
\hline Yes & $21,519(84.2)$ & $15,771(84.8)$ & $5748(82.4)$ & \\
\hline Smoking, $n(\%)$ & & & & $<0.001$ \\
\hline No & $21,243(83.1)$ & $15,660(84.2)$ & $5583(80.0)$ & \\
\hline Yes & $4326(16.9)$ & $2933(15.8)$ & $1393(20.0)$ & \\
\hline Drinking alcohol, $n(\%)$ & & & & $<0.001$ \\
\hline No & $21,175(82.8)$ & $15,586(83.8)$ & $5589(80.1)$ & \\
\hline Yes & $4394(17.2)$ & 3007 (16.2) & $1387(19.9)$ & \\
\hline Sleep quality, n (\%) & & & & 0.58 \\
\hline Not well & $22,413(87.7)$ & $16,311(87.7)$ & $6102(87.5)$ & \\
\hline Well & $3156(12.3)$ & $2282(12.3)$ & $874(12.5)$ & \\
\hline MET (hours per week) & $5.8(11.7)$ & $5.9(11.7)$ & $5.8(11.7)$ & 0.012 \\
\hline $\mathrm{BMI}\left(\mathrm{kg} / \mathrm{m}^{2}\right)$ & $23.8(4.2)$ & $23.0(3.6)$ & $26.6(3.9)$ & $<0.001$ \\
\hline Waist circumference $(\mathrm{cm})$ & $80.0(13.0)$ & $77.0(12.0)$ & $88.0(11.0)$ & $<0.001$ \\
\hline Waist-to-hip ratio & $0.8(0.1)$ & $0.8(0.1)$ & $0.9(0.1)$ & $<0.001$ \\
\hline \multicolumn{5}{|l|}{ Blood pressure (mmHg) } \\
\hline Systolic & $121.0(24.0)$ & $117.0(21.0)$ & $134.0(20.0)$ & $<0.001$ \\
\hline Diastolic & $73.0(16.0)$ & $71.0(15.0)$ & $80.0(15.0)$ & $<0.001$ \\
\hline \multicolumn{5}{|l|}{ Biomarkers (mmol/L) } \\
\hline TG & $1.2(0.9)$ & $1.0(0.7)$ & $1.9(1.1)$ & $<0.001$ \\
\hline $\mathrm{HDL}-\mathrm{C}$ & $1.4(0.5)$ & $1.5(0.5)$ & $1.2(0.4)$ & $<0.001$ \\
\hline LDL-C & $3.1(1.0)$ & $3.1(1.0)$ & $3.0(1.1)$ & $<0.001$ \\
\hline TC & $5.2(1.2)$ & $5.2(1.1)$ & $5.3(1.2)$ & $<0.001$ \\
\hline FBG & $5.6(0.7)$ & $5.5(0.6)$ & $6.0(0.9)$ & $<0.001$ \\
\hline Creatinine $(\mu \mathrm{mol} / \mathrm{L})$ & $91.1(23.0)$ & $89.3(23.0)$ & $94.6(23.9)$ & $<0.001$ \\
\hline eGFR (mL/min/1.73 m²) & $76.4(13.5)$ & $77.4(12.7)$ & $73.4(15.6)$ & $<0.001$ \\
\hline Urinary protein, $n(\%)$ & & & & $<0.001$ \\
\hline+1 & $24,464(95.7)$ & $18,133(97.5)$ & $6331(90.8)$ & \\
\hline+2 & $636(2.5)$ & $300(1.6)$ & $336(4.8)$ & \\
\hline$\geq+3$ & $469(1.8)$ & $160(0.9)$ & $309(4.4)$ & \\
\hline
\end{tabular}


Table 1 Characteristics of the participants with impaired kidney function by MetS status $(n=25,569)^{a}$ (Continued)

\begin{tabular}{|c|c|c|c|c|}
\hline & $\begin{array}{l}\text { All participants } \\
(n=25,569)\end{array}$ & $\begin{array}{l}\text { Participants without MetS } \\
(n=18,593)\end{array}$ & $\begin{array}{l}\text { Participants with MetS } \\
(n=6976)\end{array}$ & $P^{\mathrm{b}}$ \\
\hline \multicolumn{5}{|c|}{ Prevalence of chronic diseases, $n(\%)$} \\
\hline Type 2 diabetes & $2449(9.6)$ & $832(4.5)$ & $1617(23.2)$ & $<0.001$ \\
\hline Hypertension & $7450(29.1)$ & $3220(17.3)$ & $4230(60.6)$ & $<0.001$ \\
\hline Cardiovascular disease & $1519(5.9)$ & $749(4.0)$ & $770(11.0)$ & $<0.001$ \\
\hline
\end{tabular}

MetS metabolic syndrome, NTD New Taiwan dollar, MET metabolic equivalent task, BMI body mass index, TG triglycerides, $H D L-C$ high density lipoprotein cholesterol, $L D L-C$ low density lipoprotein cholesterol, TC total cholesterol, FBG fasting blood glucose, eGFR estimated glomerular filtration rate ${ }^{a}$ Continuous variables are presented as median (interquartile range). Categorical variables are presented as absolute frequency (percentage)

${ }^{\mathrm{b}}$ The $P$-values were tested using Mann-Whitney test for continuous variables and chi-square test for categorical variables

and deep fried foods, but low intakes in fruits and bread) with PCA-derived dietary pattern. As expected, the percentage of variation explained by food groups or predictors was higher in PCA-derived dietary pattern compared with that in RRR-derived dietary pattern $(15.8 \%$ vs $6.9 \%$ respectively). The RRR-derived dietary pattern explained $2.4 \%$ of the cumulative variation in six response variables and mainly driven by the explained variation in waist circumference $(5.8 \%)$ and TG (2.4\%). The detailed information of correlation coefficient and variation explained in both methods are provided in Additional file 2: Table S2.

\section{Association between dietary patterns and metabolic syndrome}

The association between PCA- or RRR-derived dietary pattern scores and MetS are presented in Table 2. The number of the participants having impaired kidney function with MetS increased across the increasing quartiles of RRR-derived dietary pattern scores. However, the number of the participants having impaired kidney function with MetS was greater in quartile 1 (Q1) and quartile 4 (Q4) of PCA-derived dietary pattern scores. Compared with the participants with impaired kidney function in the reference group (Q1), those in higher quartiles (Q3 and Q4) of PCA- or RRR-derived dietary pattern scores had $1.11-1.37$ or $1.30-1.70$ times higher odds ratios of having MetS, respectively, after adjustment for potential confounders in model 2. The association between PCA- or RRR-derived dietary pattern scores and components of MetS is illustrated in Tables 3 and 4. Participants with impaired kidney function in Q4 of PCA-derived dietary pattern scores were significantly associated with 1.64 (95\% CI: 1.46, 1.84), 1.79 (95\% CI: 1.56, 2.05), 1.25 (95\% CI: $1.15,1.35)$ and 1.21 (95\% CI: $1.12,1.31)$ times increased risk of having high waist circumference in men and women, elevated TG and

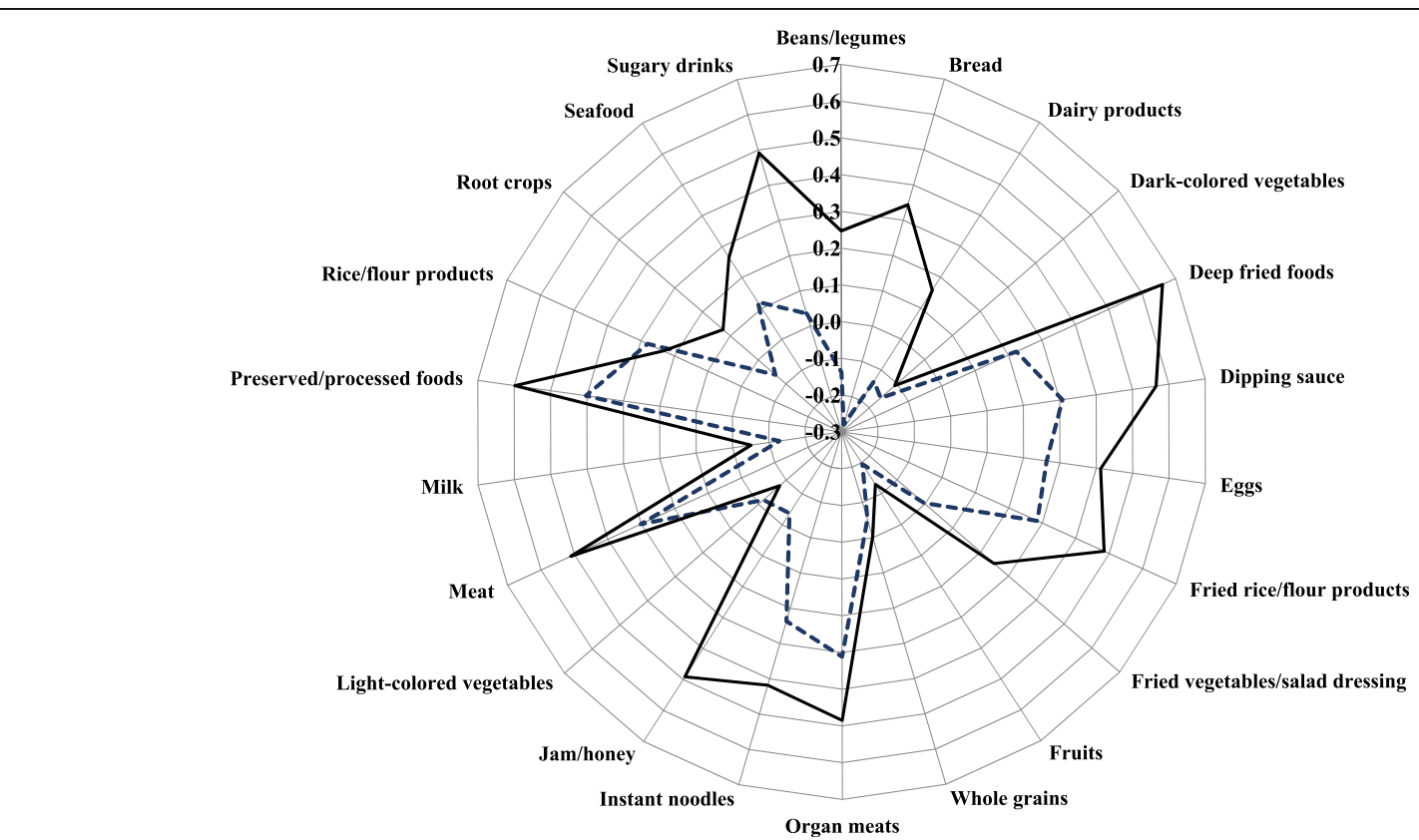

Fig. 2 Radar chart of Pearson's correlation coefficients between food groups and two dietary patterns. The dietary patterns were derived by principal component analysis (-) and reduced rank regression (---) 
Table 2 Association of PCA- or RRR-derived dietary pattern with MetS across quartiles of dietary pattern scores ${ }^{a}$

\begin{tabular}{|c|c|c|c|c|c|}
\hline & \multicolumn{4}{|c|}{ Quartiles (Q) of dietary pattern scores $(n=25,569)$} & \multirow{3}{*}{$\begin{array}{l}P- \\
\text { trend }\end{array}$} \\
\hline & $\overline{\text { Q1 }}$ & Q2 & Q3 & Q4 & \\
\hline & OR & OR (95\% Cl) & OR $(95 \% \mathrm{Cl})$ & OR $(95 \% \mathrm{Cl})$ & \\
\hline \multicolumn{6}{|c|}{ PCA-derived dietary pattern } \\
\hline Total $(n)$ & 6418 & 6365 & 6392 & 6394 & \\
\hline MetS (n) & 1762 & 1652 & 1665 & 1897 & \\
\hline Model 1 & 1 & $1.02(0.94,1.11)$ & $1.11(1.02,1.20)$ & $1.40(1.29,1.53)$ & $<0.001$ \\
\hline Model 2 & 1 & $1.03(0.95,1.12)$ & $1.11(1.02,1.21)$ & $1.37(1.26,1.49)$ & $<0.001$ \\
\hline \multicolumn{6}{|c|}{ RRR-derived dietary pattern } \\
\hline Total $(n)$ & 6403 & 6332 & 6468 & 6366 & \\
\hline MetS (n) & 1495 & 1582 & 1793 & 2106 & \\
\hline Model 1 & 1 & $1.11(1.02,1.21)$ & $1.33(1.22,1.44)$ & $1.78(1.64,1.93)$ & $<0.001$ \\
\hline Model 2 & 1 & $1.11(1.02,1.20)$ & $1.30(1.20,1.41)$ & $1.70(1.56,1.85)$ & $<0.001$ \\
\hline
\end{tabular}

$P C A$ principal component analysis, $R R R$ reduced rank regression, MetS metabolic syndrome

${ }^{a}$ Data are presented as odds ratios (ORs) and 95\% confidence intervals (95\% Cls). Model 1: adjusted for age and gender. Model 2: adjusted for age, gender, education level, income, marital status, smoking, drinking, sleep quality, physical activity and cardiovascular disease status

elevated FBG, respectively, compared with those in Q1 (Table 3). Compared with the participants with impaired kidney function in Q1, those in Q4 of RRR-derived dietary pattern scores had 1.88 (95\% CI: 1.67, 2.11), 2.14 (95\% CI: 1.87, 2.46), 1.46 (95\% CI: 1.35, 1.59) and 1.37 (95\% CI: $1.27,1.48)$ times higher odds ratios of having high waist circumference in men and women, elevated TG and elevated FBG, respectively (Table 4). Moreover, the association of RRR-derived dietary pattern scores with elevated systolic or diastolic BP ( $\mathrm{OR}=1.30$ for both $)$ and lower HDL-C in women (OR $=1.31$; $95 \% \mathrm{CI}$ : 1.13, 1.52) was statistically significant. However, the correlations of PCA-derived dietary pattern scores with elevated BP and lower HDL-C in women were not significant. After adjustment for potential confounders, PCA-derived dietary pattern scores had a linear association with all anthropometric data, biochemical parameters and blood pressure except diastolic BP (Additional file 3: Table S3). As expected, RRR-derived dietary pattern scores had stronger linear association with all anthropometric data, biochemical parameters and blood pressure compared with PCA-derived dietary pattern scores. Moreover, a subgroup analysis shown a consistent results that RRRderived dietary pattern had stronger association with risk of MetS compared with PCA-derived dietary pattern regardless of impaired kidney function categories (Additional file 4: Table S4).

\section{Discussion}

Our data supported a potential association between dietary patterns and the prevalence of MetS among middleaged and elderly adults with impaired kidney function using two different methods to derive dietary patterns. Both PCA and RRR methods produced similar dietary patterns. The dietary pattern derived by PCA method reflected dietary behavior, and the dietary pattern identified by RRR method is more likely to have a diet-disease association. The similar dietary pattern was obtained from these two methods indicating RRR-derived dietary pattern also reflects the eating behavior of the population [13]. In addition, the RRR-derived dietary pattern was more strongly associated with response variables than the PCA-derived dietary pattern. Consistent with our findings, previous studies also observed the same results in the association between dietary patterns and cardiovascular risk factors $[21,22]$ or all-cause mortality [23] among middle-aged and/or elderly adults. In addition, the RRR-derived dietary pattern had a stronger correlation with markers of subclinical atherosclerosis compared with the PCA-derived dietary pattern among multi-ethnic middle-aged and elderly adults in the United States [24]. The Growth, Exercise and Nutrition Epidemiological Study in preSchoolers (GENESIS) study also revealed that the RRR-derived dietary pattern showed a significant association with childhood obesity among Greek preschool children, but the PCA-derived dietary pattern did not have any correlation [25]. The previous studies within the framework of the Study on the Epidemiology of Psychological, Alimentary Health and Nutrition (SEPAHAN) explored the association between dietary patterns derived by PCA [26] or RRR method [27] and psychological disorders among Iranian adults. The RRR-derived healthy dietary pattern with high intake of whole grains, low-fat dairy products, vegetables, fruits and nuts had better association with a lower risk of psychological disorders compared with the PCAderived lacto-vegetarian dietary pattern $[26,27]$.

The main advantage of using RRR method to establish the dietary pattern is to incorporate the prior knowledge with better explanation of response variables rather than 
Table 3 Association of PCA-derived dietary pattern with components of MetS across quartiles of dietary pattern scores ${ }^{a}$

\begin{tabular}{|c|c|c|c|c|c|}
\hline & \multicolumn{4}{|c|}{ Quartiles (Q) of PCA-derived dietary pattern scores $(n=25,569)$} & \multirow[t]{3}{*}{$P$-trend } \\
\hline & $\begin{array}{l}\mathrm{Q1} \\
(n=6418)\end{array}$ & $\begin{array}{l}\text { Q2 } \\
(n=6365)\end{array}$ & $\begin{array}{l}\text { Q3 } \\
(n=6392)\end{array}$ & $\begin{array}{l}\text { Q4 } \\
(n=6394)\end{array}$ & \\
\hline & OR & OR $(95 \% \mathrm{Cl})$ & OR $(95 \% \mathrm{Cl})$ & OR $(95 \% \mathrm{Cl})$ & \\
\hline \multicolumn{6}{|c|}{ High waist circumference in men } \\
\hline Model 1 & 1 & $1.07(0.95,1.20)$ & $1.29(1.15,1.45)$ & $1.72(1.54,1.93)$ & $<0.001$ \\
\hline Model 2 & 1 & $1.05(0.93,1.19)$ & $1.27(1.12,1.42)$ & $1.64(1.46,1.84)$ & $<0.001$ \\
\hline \multicolumn{6}{|c|}{ High waist circumference in women } \\
\hline Model 1 & 1 & $1.07(0.95,1.22)$ & $1.26(1.11,1.44)$ & $1.78(1.55,2.04)$ & $<0.001$ \\
\hline Model 2 & 1 & $1.08(0.95,1.22)$ & $1.28(1.12,1.45)$ & $1.79(1.56,2.05)$ & $<0.001$ \\
\hline \multicolumn{6}{|c|}{ Elevated systolic BP } \\
\hline Model 1 & 1 & $0.97(0.90,1.05)$ & $0.99(0.91,1.07)$ & $1.03(0.95,1.12)$ & 0.383 \\
\hline Model 2 & 1 & $0.98(0.91,1.06)$ & $1.00(0.92,1.08)$ & $1.04(0.96,1.13)$ & 0.261 \\
\hline \multicolumn{6}{|c|}{ Elevated diastolic BP } \\
\hline Model 1 & 1 & $0.92(0.84,1.01)$ & $0.95(0.86,1.04)$ & $1.01(0.92,1.11)$ & 0.682 \\
\hline Model 2 & 1 & $0.93(0.85,1.02)$ & $0.95(0.87,1.04)$ & $1.02(0.93,1.12)$ & 0.579 \\
\hline \multicolumn{6}{|l|}{ Elevated TG } \\
\hline Model 1 & 1 & $1.02(0.94,1.11)$ & $1.12(1.03,1.21)$ & $1.30(1.20,1.41)$ & $<0.001$ \\
\hline Model 2 & 1 & $1.02(0.94,1.10)$ & $1.10(1.02,1.20)$ & $1.25(1.15,1.35)$ & $<0.001$ \\
\hline \multicolumn{6}{|c|}{ Low HDL-C in men } \\
\hline Model 1 & 1 & $0.99(0.86,1.15)$ & $1.03(0.89,1.19)$ & $1.06(0.92,1.22)$ & 0.346 \\
\hline Model 2 & 1 & $0.98(0.84,1.14)$ & $1.03(0.89,1.19)$ & $1.03(0.90,1.20)$ & 0.506 \\
\hline \multicolumn{6}{|c|}{ Low HDL-C in women } \\
\hline Model 1 & 1 & $1.02(0.90,1.16)$ & $0.91(0.79,1.05)$ & $1.11(0.96,1.29)$ & 0.394 \\
\hline Model 2 & 1 & $1.02(0.90,1.17)$ & $0.92(0.80,1.06)$ & $1.13(0.97,1.31)$ & 0.302 \\
\hline \multicolumn{6}{|c|}{ Elevated FBG } \\
\hline Model 1 & 1 & $1.06(0.99,1.14)$ & $1.02(0.95,1.10)$ & $1.21(1.12,1.30)$ & $<0.001$ \\
\hline Model 2 & 1 & $1.07(0.99,1.15)$ & $1.03(0.95,1.11)$ & $1.21(1.12,1.31)$ & $<0.001$ \\
\hline
\end{tabular}

PCA principal component analysis, MetS metabolic syndrome, BP blood pressure, $T G$ triglycerides, $H D L-C$ high density lipoprotein cholesterol, $F B G$ fasting blood glucose

${ }^{a}$ The odds ratios across quartiles of dietary pattern scores were compared with the reference group (Q1). Components of metabolic syndrome were defined as follows: high waist circumference ( $\geq 90 \mathrm{~cm}$ in men or $\geq 80 \mathrm{~cm}$ in women), elevated systolic BP ( $\geq 130 \mathrm{mmHg}$ ), elevated diastolic BP ( $\geq 85 \mathrm{mmHg}$ ), elevated TG ( $\geq$ $1.70 \mathrm{mmol} / \mathrm{L}$ ), low HDL-C ( $<1.03 \mathrm{mmol} / \mathrm{L}$ in men or $<1.30 \mathrm{mmol} / \mathrm{L}$ in women) and elevated FBG ( $\geq 5.60 \mathrm{mmol} / \mathrm{L})$. Model $1:$ adjusted for age and gender (except waist circumference and HDL-C). Model 2: adjusted for age, gender (except waist circumference and HDL-C), education level, income, marital status, smoking, drinking, sleep quality, physical activity and cardiovascular disease status

only revealing the general eating pattern in population [22]. Therefore, in most studies, RRR-derived dietary patterns were associated with disease of interest, but not necessarily reflected real-world dietary pattern [13]. In the present study, participants with high adherence to a RRR-derived dietary pattern had higher OR of having MetS compared with those with high adherence to a PCA-derived dietary pattern. Moreover, the linear regression analysis showed $\beta$ coefficients corresponding to RRR method were stronger than corresponding to PCA method. Since RRR method explicitly derives the predictors which explain the maximum of response variables, the dietary pattern identified by RRR is more likely to be closely associated with health outcomes compared with that derived by PCA [23, 28]. This argument was supported by the finding of Naja et al. [29], and the data showed that the dietary pattern derived by RRR was correlated with a higher OR of elevated BP than that derived by PCA among Lebanese adult men. This finding could be attributed to the fact that the RRR-derived dietary pattern explained more variation in response variables than the PCA-derived dietary pattern [29].

Consistent with previous studies [13, 24, 30], we used components of MetS as response variables in RRR method. In our study, RRR-derived dietary pattern was characterized by high intakes of preserved or processed foods, deep fried foods, meat and sugary drinks but low intakes of fruits and bread, which was similar to Western or unhealthy dietary pattern found in previous studies [7, 28, 31-33]. Indeed, participants with high adherence 
Table 4 Association of RRR-derived dietary pattern with components of MetS across quartiles of dietary pattern scores ${ }^{a}$

\begin{tabular}{|c|c|c|c|c|c|}
\hline & \multicolumn{4}{|c|}{ Quartiles (Q) of RRR-derived dietary pattern scores $(n=25,569)$} & \multirow[t]{3}{*}{$P$-trend } \\
\hline & $\begin{array}{l}\text { Q1 } \\
(n=6403)\end{array}$ & $\begin{array}{l}\text { Q2 } \\
(n=6332)\end{array}$ & $\begin{array}{l}\text { Q3 } \\
(n=6468)\end{array}$ & $\begin{array}{l}\text { Q4 } \\
(n=6366)\end{array}$ & \\
\hline & OR & OR $(95 \% \mathrm{Cl})$ & OR $(95 \% \mathrm{Cl})$ & OR $(95 \% \mathrm{Cl})$ & \\
\hline \multicolumn{6}{|c|}{ High waist circumference in men } \\
\hline Model 1 & 1 & $1.17(1.03,1.32)$ & $1.27(1.13,1.43)$ & $2.00(1.78,2.24)$ & $<0.001$ \\
\hline Model 2 & 1 & $1.16(1.02,1.31)$ & $1.23(1.09,1.39)$ & $1.88(1.67,2.11)$ & $<0.001$ \\
\hline \multicolumn{6}{|c|}{ High waist circumference in women } \\
\hline Model 1 & 1 & $1.09(0.96,1.24)$ & $1.68(1.48,1.90)$ & $2.20(1.92,2.53)$ & $<0.001$ \\
\hline Model 2 & 1 & $1.08(0.95,1.22)$ & $1.65(1.45,1.87)$ & $2.14(1.87,2.46)$ & $<0.001$ \\
\hline \multicolumn{6}{|c|}{ Elevated systolic BP } \\
\hline Model 1 & 1 & $1.03(0.96,1.12)$ & $1.14(1.05,1.23)$ & $1.32(1.22,1.43)$ & $<0.001$ \\
\hline Model 2 & 1 & $1.03(0.95,1.11)$ & $1.13(1.04,1.22)$ & $1.30(1.20,1.41)$ & $<0.001$ \\
\hline \multicolumn{6}{|c|}{ Elevated diastolic BP } \\
\hline Model 1 & 1 & $1.04(0.95,1.14)$ & $1.10(1.01,1.21)$ & $1.32(1.21,1.45)$ & $<0.001$ \\
\hline Model 2 & 1 & $1.04(0.94,1.14)$ & $1.10(1.00,1.20)$ & $1.30(1.19,1.43)$ & $<0.001$ \\
\hline \multicolumn{6}{|l|}{ Elevated TG } \\
\hline Model 1 & 1 & $1.09(1.01,1.18)$ & $1.28(1.18,1.38)$ & $1.56(1.44,1.69)$ & $<0.001$ \\
\hline Model 2 & 1 & $1.08(0.99,1.17)$ & $1.24(1.14,1.34)$ & $1.46(1.35,1.59)$ & $<0.001$ \\
\hline \multicolumn{6}{|c|}{ Low HDL-C in men } \\
\hline Model 1 & 1 & $0.96(0.83,1.11)$ & $1.00(0.87,1.16)$ & $1.06(0.92,1.21)$ & 0.364 \\
\hline Model 2 & 1 & $0.96(0.83,1.12)$ & $0.99(0.86,1.15)$ & $1.04(0.90,1.21)$ & 0.482 \\
\hline \multicolumn{6}{|c|}{ Low HDL-C in women } \\
\hline Model 1 & 1 & $1.13(0.99,1.29)$ & $1.14(0.99,1.30)$ & $1.31(1.13,1.52)$ & $<0.001$ \\
\hline Model 2 & 1 & $1.13(0.99,1.28)$ & $1.13(0.98,1.29)$ & $1.31(1.13,1.52)$ & $<0.001$ \\
\hline \multicolumn{6}{|c|}{ Elevated FBG } \\
\hline Model 1 & 1 & $1.11(1.04,1.20)$ & $1.19(1.10,1.28)$ & $1.37(1.27,1.48)$ & $<0.001$ \\
\hline Model 2 & 1 & $1.12(1.04,1.20)$ & $1.18(1.10,1.28)$ & $1.37(1.27,1.48)$ & $<0.001$ \\
\hline
\end{tabular}

RRR reduced rank regression, MetS metabolic syndrome, BP blood pressure, TG triglycerides, HDL-C high density lipoprotein cholesterol, $F B G$ fasting blood glucose ${ }^{a}$ The odds ratios across quartiles of dietary pattern scores were compared with the reference group (Q1). Components of metabolic syndrome were defined as follows: high waist circumference $(\geq 90 \mathrm{~cm}$ in men or $\geq 80 \mathrm{~cm}$ in women), elevated systolic BP $(\geq 130 \mathrm{mmHg})$, elevated diastolic BP $(\geq 85 \mathrm{mmHg})$, elevated TG $(\geq$ $1.70 \mathrm{mmol} / \mathrm{L})$, low HDL-C $(<1.03 \mathrm{mmol} / \mathrm{L}$ in men or $<1.30 \mathrm{mmol} / \mathrm{L}$ in women) and elevated FBG ( $\geq 5.60 \mathrm{mmol} / \mathrm{L})$. Model 1: adjusted for age and gender (except waist circumference and HDL-C). Model 2: adjusted for age, gender (except waist circumference and HDL-C), education level, income, marital status, smoking, drinking, sleep quality, physical activity and cardiovascular disease status

to this dietary pattern had a positive association with the prevalence of MetS. Although the lower but significant correlations of PCA-derived dietary pattern with components of MetS compared with that of RRR-derived dietary pattern, the similar results were found regarding the association between PCA- or RRR-derived dietary pattern and components of MetS. In consistent with the previous findings using PCA method to derive the dietary pattern, a Western-type dietary pattern with high intake of white bread, processed meat, fries, hamburger, hot dog and salty snacks was associated with a higher risk of developing MetS [34]. In the present study, both PCA- and RRRderived dietary patterns showed significant correlations with all metabolic components, but PCA-derived dietary pattern was not associated with diastolic BP.
Several possible mechanisms may explain the linear effect of unhealthy dietary pattern and the components of MetS. The food components of this dietary pattern such as preserved or processed foods, deep fried foods, meat and sugary drinks plausibly contribute to an increased risk of MetS. This dietary pattern was often accompanied by high intakes of total fat, saturated fat and simple sugar which may stimulate the production and secretion of certain pro-inflammatory cytokines including Creactive protein (CRP) and further increase systemic inflammation [24, 30, 35]. The pro-inflammatory cytokine CRP has been known to be closely related to inflammation and MetS [36]. Our previous study demonstrated that participants who consumed high intake of a Western-type dietary pattern had increased odds of 
components of MetS and CRP [37]. The plausible mechanisms for the effect of CRP on the increased risk of MetS included the impairment of insulin signaling pathway and pro-atherogenic effects on vascular cells [38]. Chronic inflammation was associated with insulin resistance, dyslipidemia and elevated BP [29, 35]. Participants with higher adherence to a Western diet tended to have higher prevalence of hypertension, which may be partially correlated with high intakes of fat and protein from animal food sources in this particular dietary pattern $[39,40]$. The International Study on Macro/Micronutrients and Blood Pressure (INTERMAP) study also reported a significant linear association between total protein intake and blood pressure [41]. Additionally, high consumption of red meat dietary pattern could be correlated with deposition of iron, particularly hemeiron. Subjects in the MetS group had an elevated iron overload than those in the age-matched control group [42]. Therefore, high iron contents in red meat might be related to an increased prevalence of MetS [42-45]. A recent meta-analysis study indicated that adherence to a posteriori meat/Western dietary pattern characterized by high intakes of meat, processed foods and fast foods significantly increased risk of MetS by 19\% [33]. Similarly, other studies found that meat/Western dietary pattern was associated with an increased risk of MetS by $16 \%$ [31] to $28 \%$ [32].

The major strength of our study was the use of different approaches to derive dietary patterns and comparison of these two results. The similar dietary patterns obtained from PCA and RRR methods might indicate dietary behavior, which was assumed to be on the causal pathway from dietary pattern to the disease of interest. Furthermore, we had a large study population that could describe the dietary pattern in a greater scale. However, several limitations in the present study should be considered. First, the limitation of the study was the crosssectional design, which made it difficult to have causal inference. Secondly, in corresponding with a previous study [32], many possible confounding factors (demographic and lifestyle factors) had been controlled in the present study, yet we were not able to control other factors such as total energy and protein intake, family history of diabetes, hypertension or cardiovascular disease and intake of other drugs. These unmeasured factors may have introduced residual confounding. Lastly, although the questionnaire in this study had been validated for Taiwanese population, dietary intake was assessed using self-administered SQ-FFQ and underreporting may occur.

\section{Conclusion}

In summary, both PCA and RRR methods obtain a similar dietary pattern which is associated with components of MetS among middle-aged and elderly adults with impaired kidney function. This similarity allows to assess the likeness between real eating behavior and MetS-related dietary patterns. Even though both dietary patterns have a linear association with components of MetS, RRR method shows stronger statistical correlations. Therefore, RRR method may be more suitable to evaluate dietary information for designing and realizing dietary guidelines. Moreover, adequate dietary intake in people with impaired kidney function is important to manage kidney disease, and designing dietary guidelines based on dietary pattern analysis by incorporating kidney function biomarkers as the response variables is necessary to prevent the severity of kidney disease. However, further research is needed to confirm the association between RRR-derived dietary pattern and other disease outcomes in combination with prospective measurements.

\section{Supplementary information}

Supplementary information accompanies this paper at https://doi.org/10. 1186/s12874-020-01142-4.

Additional file 1: Table S1. Food groups used in the dietary pattern analysis.

Additional file 2: Table S2-1. Factor loadings (Pearson's correlation coefficients) of food groups in PCA-derived dietary patterns ${ }^{\text {a }}$. Table S22. Percentage of variation and Pearson's correlation coefficients among food groups and response variables in RRR-derived dietary pattern.

Additional file 3: Table S3. Linear associations of PCA- or RRR-derived dietary pattern scores with components of MetS.

Additional file 4: Table S4. Association of PCA- or RRR-derived dietary pattern with MetS in subgroups by impaired kidney function ${ }^{\text {a }}$

\section{Abbreviations}

BMI: Body mass index; BP: Blood pressure; eGFR: Estimated glomerular filtration rate; FBG: Fasting blood glucose; HDL-C: High density lipoprotein cholesterol; LDL-C: Low density lipoprotein cholesterol; MET: Metabolic equivalent task; MetS: Metabolic syndrome; MJ: Mei Jau; PCA: Principal component analysis; RRR: Reduced rank regression; SQ-FFQ: Food frequency questionnaire; TC: Total cholesterol; TG: Triglycerides

\section{Acknowledgements}

The authors thank to Mei Jau Health Institute for collecting and providing their database available for this study.

\section{Authors' contributions}

ALK and JCJC conceived and designed the study; CYH, HAL and HHR managed and retrieved the data; ALK and AS analyzed the data and performed the statistical analysis; ALK, RP and JCJC wrote the manuscript. All authors have read and approved the final version of manuscript.

\section{Funding}

This research received no external funding.

\section{Availability of data and materials}

The data that support the findings of this study are available from Mei Jau (MJ) Health Institute, but restricted for research use only. The data are not publicly available. Data are available from the authors upon reasonable request and with permission of MJ Health Institute. 


\section{Ethics approval and consent to participate}

The study was approved by the Taipei Medical University-Joint Institutional Review Board (TMU-JIRB) no. 201802006. All the participants signed a written informed consent authorized by Mei Jau Health Institute.

\section{Consent for publication}

The data provided by Mei Jau Health Institute to the researchers did not include any personal information, and all participants were adults. Not applicable.

\section{Competing interests}

The authors declare no conflict of interest.

\section{Author details}

${ }^{1}$ School of Nutrition and Health Sciences, College of Nutrition, Taipei Medical University, 250 Wu-Hsing Street, Taipei 11031, Taiwan. ${ }^{2}$ Research Center for Healthcare Industry Innovation, National Taipei University of Nursing and Health Sciences, 365 Ming-Te Road, Peitou District, Taipei 11219, Taiwan. ${ }^{3}$ Department of Information Management, National Taipei University of Nursing and Health Sciences, 365 Ming-Te Road, Peitou District, Taipei 11219, Taiwan. ${ }^{4}$ Master Program in Global Health and Development, College of Public Health, Taipei Medical University, 250 Wu-Hsing Street, Taipei 11031, Taiwan. ${ }^{5}$ Department of Computer Science and Information Engineering, Tamkang University, 151 Yingzhuan Road, Tamsui District, New Taipei 25137, Taiwan. ${ }^{6} J o i n t$ Commission of Taiwan, 31 Sec.2 Sanmin Road, Banqiao District 220, New Taipei City, Taiwan. ${ }^{7}$ Department of Nutrition Science, Faculty of Medicine, Diponegoro University, Jl. Prof. H. Soedarto, SH, Tembalang, Semarang City, Central Java 50275, Indonesia. ${ }^{8}$ Nutrition Research Center, Taipei Medical University Hospital, 252 Wu-Hsing Street, Taipei 11031, Taiwan.

\section{Received: 17 May 2020 Accepted: 7 October 2020}

Published online: 14 October 2020

\section{References}

1. Arai H, Yamamoto A, Matsuzawa Y, Saito Y, Yamada N, Oikawa S, et al. Prevalence of the metabolic syndrome in elderly and middle-aged Japanese. J Clin Gerontol. 2010;1:42-7.

2. Alberti KGMM, Zimmet P, Shaw J. Metabolic syndrome-a new world-wide definition. A consensus statement from the international diabetes federation. Diabet Med. 2006;23:469-80.

3. Thomas G, Sehgal AR, Kashyap SR, Srinivas TR, Kirwan JP, Navaneethan SD. Metabolic syndrome and kidney disease: a systematic review and metaanalysis. Am Soc Nephrol. 2011;6:2364-73.

4. Tsangalis G, Papaconstantinou S, Kosmadakis G, Valis D, Zerefos N Prevalence of the metabolic syndrome in hemodialysis. Int J Artif Organs. 2007;30:118-23.

5. AlShelleh S, AlAwwa I, Oweis A, AlRyalat SA, Al-Essa M, Saeed I, et al. Prevalence of metabolic syndrome in dialysis and transplant patients. Diabetes Metab Syndr Obes. 2019;12:575-9.

6. Newby $\mathrm{P}$, Tucker KL. Empirically derived eating patterns using factor or cluster analysis: a review. Nutr Rev. 2004;62:177-203.

7. Hu FB. Dietary pattern analysis: a new direction in nutritional epidemiology. Curr Opin Lipidol. 2002;13:3-9.

8. Lutsey PL, Steffen LM, Stevens J. Dietary intake and the development of the metabolic syndrome: the atherosclerosis risk in communities study. Circulation. 2008;117:754-61.

9. Panagiotakos DB, Pitsavos C, Skoumas Y, Stefanadis C. The association between food patterns and the metabolic syndrome using principal components analysis: the ATTICA study. J Am Diet Assoc. 2007;107:979-87.

10. Reedy J, Wirfält E, Flood A, Mitrou PN, Krebs-Smith SM, Kipnis V, et al. Comparing 3 dietary pattern methods-cluster analysis, factor analysis, and index analysis-with colorectal cancer risk: the NIH-AARP diet and health study. Epidemiol. 2009;171:479-87.

11. Frank L, Jannasch F, Kröger J, Bedu-Addo G, Mockenhaupt F, Schulze M, et al. A dietary pattern derived by reduced rank regression is associated with type 2 diabetes in an urban Ghanaian population. Nutrients. 2015;7: 5497-514.

12. Batis C, Mendez MA, Gordon-Larsen P, Sotres-Alvarez D, Adair L, Popkin B. Using both principal component analysis and reduced rank regression to study dietary patterns and diabetes in Chinese adults. Public Health Nutr. 2016;19:195-203.
13. Barbaresko J, Siegert S, Koch M, Aits I, Lieb W, Nikolaus S, et al. Comparison of two exploratory dietary patterns in association with the metabolic syndrome in a northern German population. Br J Nutr. 2014;112:1364-72.

14. Levey AS, Stevens LA, Schmid CH, Zhang YL, Castro AF, Feldman HI, et al. A new equation to estimate glomerular filtration rate. Ann Intern Med. 2009; 150:604-12.

15. Kurniawan AL, Hsu CY, Rau HH, Lin LY, Chao JCJ. Association of kidney function-related dietary pattern, weight status, and cardiovascular risk factors with severity of impaired kidney function in middle-aged and older adults with chronic kidney disease: a cross-sectional population study. Nutr J. 2019;18:27.

16. Grundy SM, Cleeman JI, Daniels SR, Donato KA, Eckel RH, Franklin BA, et al. Diagnosis and management of the metabolic syndrome: an American Heart Association/National Heart, Lung, and Blood Institute scientific statement. Circulation. 2005;112:2735-52.

17. MJ Group. MJ health screening center questionnaire QR-121-1 MJ2011.061104TW. http://www.mjlife.com/index.aspx?lang=eng\&fn=mj. Acessed 20 Feb 2018.

18. Lyu LC, Lin CF, Chang FH, Chen HF, Lo CC, Ho HF. Meal distribution, relative validity and reproducibility of a meal-based food frequency questionnaire in Taiwan. Asia Pac J Clin Nutr. 2007;16:766-76.

19. Muga MA, Owili PO, Hsu CY, Rau HH, Chao JCJ. Association between dietary patterns and cardiovascular risk factors among middle-aged and elderly adults in Taiwan: a population-based study from 2003 to 2012. PLoS One. 2016;11:e0157745.

20. Jette M, Sidney K, Blumchen G. Metabolic equivalents (METS) in exercise testing, exercise prescription, and evaluation of functional capacity. Clin Cardiol. 1990;13:555-65.

21. Sauvageot N, Leite S, Alkerwi A, Sisanni L, Zannad F, Saverio S, et al. Association of empirically derived dietary patterns with cardiovascular risk factors: a comparison of PCA and RRR methods. PLoS One. 2016;11: e0161298.

22. Centritto F, lacoviello L, di Giuseppe R, De Curtis A, Costanzo S, Zito F, et al. Dietary patterns, cardiovascular risk factors and C-reactive protein in a healthy Italian population. Nutr Metab Cardiovasc Dis. 2009;19:697-706.

23. Hoffmann $K$, Boeing $H$, Boffetta $P$, Nagel G, Orfanos $P$, Ferrari $P$, et al. Comparison of two statistical approaches to predict all-cause mortality by dietary patterns in German elderly subjects. Br J Nutr. 2005;93:709-16.

24. Nettleton JA, Steffen LM, Schulze MB, Jenny NS, Barr RG, Bertoni AG, et al. Associations between markers of subclinical atherosclerosis and dietary patterns derived by principal components analysis and reduced rank regression in the multi-ethnic study of atherosclerosis (MESA). Am J Clin Nutr. 2007;85:1615-25

25. Manios Y, Kourlaba G, Grammatikaki E, Androutsos O, loannou E, RomaGiannikou E. Comparison of two methods for identifying dietary patterns associated with obesity in preschool children: the GENESIS study. Eur J Clin Nutr. 2010;64:1407-14.

26. Hosseinzadeh M, Vafa MR, Esmaillzadeh A, Feizi A, Majdzadeh R, Afshar H, et al. Empirically derived dietary patterns in relation to psychological disorders. Public Health Nutr. 2016;19:204-17.

27. Hosseinzadeh M, Vafa MR, Esmaillzadeh A, Feizi A, Majdzadeh R, Afshar H, et al. Psychological disorders and dietary patterns by reduced-rank regression. Eur J Clin Nutr. 2019;73:408-15.

28. Wolters M, Joslowski G, Plachta-Danielzik S, Standl M, Müller M, Ahrens W, et al. Dietary patterns in primary school are of prospective relevance for the development of body composition in two German pediatric populations. Nutrients. 2018;10:1442.

29. Naja F, Itani L, Hwalla N, Sibai AM, Kharroubi SA. Identification of dietary patterns associated with elevated blood pressure among Lebanese men: a comparison of principal component analysis with reduced rank regression and partial least square methods. PLoS One. 2019;14:e0220942.

30. Vujkovic M, Steegers EA, Looman CW, Ocké MC, van der Spek PJ, SteegersTheunissen RP. The maternal Mediterranean dietary pattern is associated with a reduced risk of spina bifida in the offspring. Int J Gynaecol Obstet. 2009;116:408-15.

31. Shab-Bidar S, Golzarand M, Hajimohammadi M, Mansouri S. A posteriori dietary patterns and metabolic syndrome in adults: a systematic review and meta-analysis of observational studies. Public Health Nutr. 2018;21:1681-92.

32. Rodríguez-Monforte M, Sánchez E, Barrio F, Costa B, Flores-Mateo G. Metabolic syndrome and dietary patterns: a systematic review and metaanalysis of observational studies. Eur J Clin Nutr. 2017;56:925-47. 
33. Fabiani R, Naldini G, Chiavarini MJN. Dietary patterns and metabolic syndrome in adult subjects: a systematic review and meta-analysis. Nutrients. 2019;11:2056.

34. Agodi A, Maugeri A, Kunzova S, Sochor O, Bauerova H, Kiacova N, et al. Association of dietary patterns with metabolic syndrome: results from the Kardiovize Brno 2030 study. Nutrients. 2018;10:898.

35. Deng FE, Shivappa N, Tang Y, Mann JR, Hebert JR. Association between diet-related inflammation, all-cause, all-cancer, and cardiovascular disease mortality, with special focus on prediabetics: findings from NHANES III. Eur J Clin Nutr. 2017;56:1085-93.

36. Naja F, Shivappa N, Nasreddine L, Kharroubi S, Itani L, Hwalla N, et al. Role of inflammation in the association between the western dietary pattern and metabolic syndrome among Lebanese adults. Int J Food Sci Nutr. 2017;68: 997-1004.

37. Syauqy A, Hsu CY, Rau HH, Chao JCJ. Association of dietary patterns with components of metabolic syndrome and inflammation among middle-aged and older adults with metabolic syndrome in Taiwan. Nutrients. 2018;10:143.

38. Sproston NR, Ashworth JJ. Role of C-reactive protein at sites of inflammation and infection. Front Immunol. 2018;9:754.

39. Nikniaz L, Nikniaz Z, Sadeghi-Bazargani H, Abdollahi HM, Farhangi MA. Association between major dietary patterns and metabolic syndrome components: a population-based study from north-west of Iran. Int J Diabetes Dev Countries. 2019;39:721-9.

40. Sabour H, Norouzi-Javidan A, Soltani Z, Mousavifar SA, Latifi S, Emami-Razavi $\mathrm{SH}$, et al. The correlation between dietary fat intake and blood pressure among people with spinal cord injury. Iran J Neurol. 2016;15:121-7.

41. Elliott P, Stamler J, Dyer AR, Appel L, Dennis B, Kesteloot H, et al. Association between protein intake and blood pressure: the INTERMAP Study. JAMA Intern Med. 2006;166:79-87.

42. Bozzini C, Girelli D, Olivieri O, Martinelli N, Bassi A, De Matteis G, et al. Prevalence of body iron excess in the metabolic syndrome. Diabetes Care. 2005;28:2061-3.

43. Woo HD, Shin A, Kim JJPO. Dietary patterns of Korean adults and the prevalence of metabolic syndrome: a cross-sectional study. PLoS One. 2014; 9:e111593.

44. Sun L, Franco OH, Hu FB, Cai L, Yu Z, Li H, et al. Ferritin concentrations, metabolic syndrome, and type 2 diabetes in middle-aged and elderly Chinese. J Clin Endocrinol Metab. 2008:93:4690-6.

45. Azadbakht L, Esmaillzadeh A. Red meat intake is associated with metabolic syndrome and the plasma C-reactive protein concentration in women. Nutr J. 2008;139:335-9.

\section{Publisher's Note}

Springer Nature remains neutral with regard to jurisdictional claims in published maps and institutional affiliations.

Ready to submit your research? Choose BMC and benefit from:

- fast, convenient online submission

- thorough peer review by experienced researchers in your field

- rapid publication on acceptance

- support for research data, including large and complex data types

- gold Open Access which fosters wider collaboration and increased citations

- maximum visibility for your research: over $100 \mathrm{M}$ website views per year

At $\mathrm{BMC}$, research is always in progress.

Learn more biomedcentral.com/submissions 